\title{
Competitive Incentives: Working Harder or Working Smarter?
}

\author{
Anat Bracha and Chaim Fershtman
}

\begin{abstract}
:
Almost all jobs require a combination of cognitive effort and labor effort. This paper focuses on the effect that competitive incentive schemes have on the chosen combination of these two types of efforts. We use an experimental approach to show that competitive incentives may induce agents to work harder but not necessarily smarter. This effect was stronger for women.
\end{abstract}

\section{JEL Classifications: J33, D03}

Anat Bracha is an economist at the Federal Reserve Bank of Boston. Her e-mail address is anat.bracha@bos.frb.org. Chaim Fershtman is a professor of economics at Tel Aviv University, and a research fellow at the Centre for Economic Policy Research and at the Tinbergen Institute. His e-mail address is fersht@post.tau.ac.il.

The work presented in this paper was supported by Grant No. 0610114192 from the Israel Science Foundation.

The authors thank Lynn Connell-Price for her excellent research assistance.

This paper presents preliminary analysis and results intended to stimulate discussion and critical comment. The views expressed herein are those of the authors and do not indicate concurrence by the Federal Reserve Bank of Boston, or by the principals of the Board of Governors, or the Federal Reserve System.

This paper, which may be revised, is available on the web site of the Federal Reserve Bank of Boston at http://www.bostonfed.org/economic/wp/index.htm.

This version: October 11, 2012 


\section{Introduction}

Competitive incentives are commonly used by firms and modern organizations to motivate their workers. While competitive incentives have proven to be effective in inducing more effort, the focus of this paper is whether such incentives induce individuals to work smarter, or just to work harder.

Almost all jobs require a combination of cognitive effort and labor effort. Research and development (R\&D), running a company, building a house, teaching a class, or working on a factory floor requires both cognitive and labor efforts. The tradeoff between these two types of effort exists whenever agents need to think about how to perform a task or to choose a method of solving a problem before they actually implement it. For instance, consider the task of trying to find the highest value of a function: people may try to analyze the function (cognitive effort), they may try to check it for many parameter values (labor effort), or they may attempt a combination of the two methods. It is the combination of cognitive and labor effort that determines whether people work harder or smarter.

The general intuition holds that providing competitive incentives motivates individuals to exert more effort. ${ }^{1}$ But once we distinguish between cognitive and labor efforts an additional question arises: what is the effect of different incentive schemes on the combination of the two types of efforts? If different incentive schemes do indeed influence workers' chosen combination of effort this could be important for firms, as different firms may wish to elicit different combinations of effort. Firms that specialize in $R \& D$ and innovation, for instance, may want workers to exert more cognitive effort - to work smarter-while some manufacturing firms may wish to motivate workers' labor effort - to work harder. The main application of our study is that the optimal incentive scheme also depends on the type of effort firms wish to elicit.

To answer the question of whether incentive schemes affect the chosen combination of effort, we consider and examine players' effort allocation under two types of incentives: (i) a simple pay-for-performance incentive scheme (hereinafter PFP), in which agents are paid according to their own performance, and (ii) tournament incentives

\footnotetext{
${ }^{1}$ For a survey see Lazear (2000).
} 
in which pairs of participants compete for a prize. Our claim is that, due to competitive pressure, competitive incentives will lead participants to exert less cognitive effort but more labor effort, relative to PFP. That is, we expect that under a competitive incentive scheme participants will work harder but not smarter.

This conjecture is related to the psychological literature identifying several mechanisms that result in "choking under pressure." This literature suggests that pressure in various forms such as large stakes, performing in front of an audience, and competition may lower performance in various types of tasks (see, for example, Baumeister 1984; Baumeister and Showers 1986; Beilock, Kulp, Holt, and Carr 2004). In economics, Ariely, Gneezy, Loewenstein, and Mazar (2009) recently demonstrated the choking under pressure effect and showed that excessively high rewards have a detrimental effect on performance. However, choking under pressure does not necessarily occur in all circumstances: for instance, Beilock, Kulp, Holt, and Carr (2004) show that pressure adversely affects performance in solving novel but not heavily practiced math problems, ${ }^{2}$ whereas solving novel math problems requires high working memory-cognitive effort - while the practiced questions do not.

To test our claim that under competition people will work harder, not smarter, we designed a simple lab experiment with two computerized tasks, a "sequences" task where participants were asked to solve numeric sequences that require cognitive effort and a "filing" task that is a simple number categorizing task mainly requiring manual dexterity. Participants in this study could engage in either task and were free to switch between the two during the entire duration of the experiment. In examining performance across the two incentive schemes we focus on whether the competitive incentives affected time allocation between the sequences task and the filing task as well as the players' success rate in solving sequences, compared with $\mathrm{PFP}^{3}$

Our main results are that under competitive incentives participants devote less time to the sequences task and have a lower success rate than when they are provided with PFP incentives. In other words, the tournament incentive did indeed lead participants to work harder but not smarter.

\footnotetext{
2 To correctly answer a practiced problem one only needed to retrieve the solution from memory.

${ }^{3}$ Success rate is the percentage of sequences solved correctly over the number of sequences attempted.
} 
However, our results are gender sensitive. Under the PFP incentives the performance of women is lower than the performance of men, as women attempted to solve less sequences and devoted more of the allotted time to the simpler task of categorizing numbers. This is despite the fact that in the PFP treatment men and women had the same success rate in solving sequences. Analyzing the effect of competitive incentives by gender, we find that relative to the PFP treatment, competitive incentives induce both men and women to spend less time on the sequences task and more on the routine filing task. However, the negative effect of the competitive incentives on the success rate is entirely a female effect.

This paper adds to the experimental investigation of tournament relative to pay-forperformance incentives (see, for example, Bull, Schotter, and Weigelt 1987) and the recent literature on gender differences in response to competition (for example, Gneezy, Niederle, and Rustichini 2003; for a survey see Croson and Gneezy 2009 and Bertrand 2011). However, previous studies either use nonreal effort settings where effort is a number chosen by a participant in the study, or a real-effort task which requires one type of effort. Hence, this paper adds to the literature by considering a new aspect of competitive incentives-its effect on effort allocation-and points at the differential effect that competition has on effort allocation across gender.

This paper also adds to the recent literature on the psychological foundation of incentives, which provides an important critical view of the traditional incentive theory (for a survey see Fehr and Falk 2002). The main claim in this literature is that considering monetary incentives alone is too narrow, empirically questionable, and limits our understanding of incentives. Nonpecuniary motives such as reciprocity, the desire for social status, and fairness concerns are powerful drivers of human motivation. Our results extend this literature by focusing on the combination of cognitive and labor effort.

\section{Experimental Design}

To capture the two different types of effort we introduced two tasks, each of which emphasized either cognitive or labor effort. Subjects could freely choose to engage in either solving sequences ("sequences" task) — finding a missing number in a sequence of four numbers - or classifying a random number into an "odd" or "even" category ("filing" task) by pressing the appropriate button on the computer screen. The sequences 
task requires cognitive effort in the form of abstract thinking, while filing numbers mainly requires labor effort. Both tasks were available during the experiment, and engaging in each of the two tasks was done by simply clicking on the section of the screen with the desired task (see figure 1).

Figure 1: Sequences Task and Filing Task

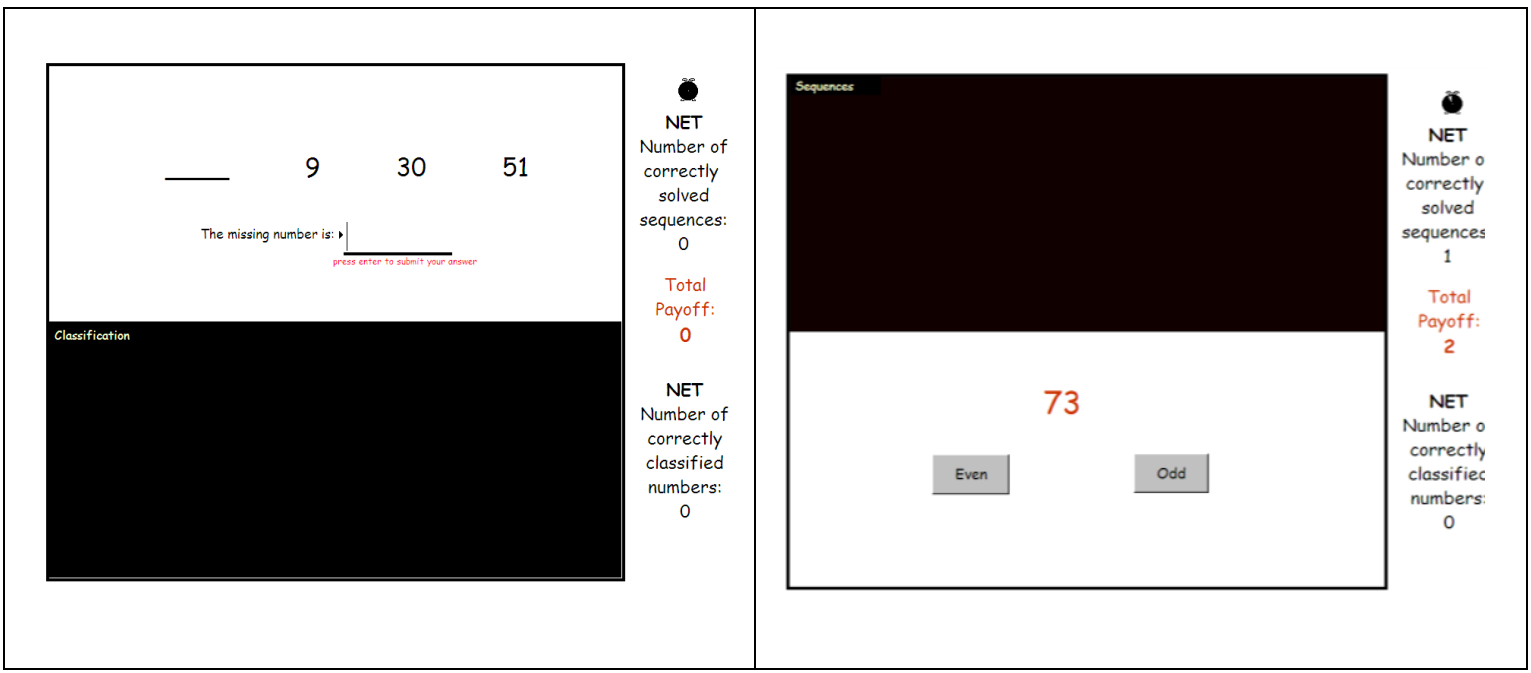

Source: Authors' calculations.

\subsection{Treatments}

To analyze the effect of incentives we use a between-subject design with two treatments: Pay for Performance and head-to-head tournament. In our experimental design the goal was to earn money, and the complementarity between the tasks was achieved using the compensation scheme described below.

Pay-for-Performance (PFP): subjects were paid \$2 per net correctly solved sequences, 3 cents per net correctly filed numbers, and a 1 cent extra reward for the product obtained by multiplying the net sequences by the net filed numbers. ${ }^{4}$ The net number of correctly solved sequences is the number of correctly solved sequences minus half the number of incorrectly solved sequences. Penalizing incorrectly solved sequences was designed to prevent guessing. The net filed numbers equals the correctly filed numbers minus the incorrectly filed numbers. Penalizing incorrectly filed numbers was designed to prevent random clicking. The extra reward introduces a complementary term, as a greater number

\footnotetext{
${ }^{4}$ This compensation is different from a piece rate since there is a multiplicative term in their incentives.
} 
of net correctly solved sequences (filed numbers) increases the marginal return to successful filing (sequence).

Tournament: in this treatment, subjects were randomly paired using a randomly generated subject identification (ID) number. The pairs were announced before the beginning of the task and by subject ID, such that the identity of one's opponent was not revealed. The winner was determined according to the accumulated number of points for each of the opponents in a pair. The point schedule was exactly the same as under the PFP compensation scheme-2 points per net sequence, 0.03 of a point per net number filed and an extra 0.01 of a point for the product of net sequences times the net numbers filed. The winner's prize was $\$ 60$, and the loser received the minimum guarantee of $\$ 10$, such that the expected earning was $\$ 35$, similar to the average earning under PFP. At the end of the study, after completing the time devoted to the task, the accumulated number of points for each participant was announced (by the randomly generated subject ID), and the earnings were determined and announced.

\subsection{Procedure}

The sessions were conducted at the Harvard Decision Science Laboratory at the Harvard Kennedy School. A total of 134 Harvard students participated in the study, 74 in the PFP treatment and 60 in the tournament treatment. In each session, participants sat at individual computer stations and read the instructions on their individual screens. Once all were done with the instructions, they were given a code to proceed such that all started working on the task at the same time. Under both conditions, they were given 10 minutes to work on the two tasks. In the tournament treatment, once all were done with the instructions, and before giving the code to proceed, the experimenter announced the pairs by subject ID.

\section{Competitive Incentives}

Economic intuition suggests that competitive incentives may induce individuals to 
exert more effort. ${ }^{5}$ But individuals may also react to the pressure created by the competitive incentives. Competitive pressure may have different effects on cognitive and labor effort. Competitive pressure may affect cognitive and labor efforts differently. Our main hypothesis is that competitive pressure mainly affects cognitive effort by making it more difficult or more costly to perform cognitive tasks.

Hypothesis 1: (i) Competitive incentives induce individuals to reduce their cognitive effort while increasing their labor effort. (ii) Competitive incentives reduce the effectiveness of cognitive effort which results in a lower success rate.

In our experiment individuals were given ten minutes to engage in the two tasks. This time limit may have created an additional type of pressure-time pressure. We expect that the time pressure, if it exists, will be stronger at the end of the given time frame and that time pressure will be stronger in the tournament treatment, as earning an additional point may be the decisive factor for winning the tournament.

Hypothesis 2: Time pressure will be effective in the tournament treatment resulting in lower success rates at the end of the tournament relative to those at the beginning of the tournament. ${ }^{6}$ In the tournament treatment, time pressure will affect performance and result in lower success rates at the end of the tournament relative to the beginning of the tournament.

To test these hypotheses we examine the time allocation between the two tasks and the success rate in solving sequences. The comparison is provided in Table $1 .{ }^{7}$

\footnotetext{
${ }^{5}$ See Lazear and Rosen (1981) for a theoretical argument. Empirically, Ehrenberg and Bognanno (1990) demonstrate the positive effect of tournament incentives on effort in golf tournaments, and Kremer, Miguel, and Thornton(2009) find that for girls in Kenya, competing forscholarships has a positive effect on their scholastic achievement. Experimentally, the results of studies such as Gneezy, Niederle, and Rustichini (2003) and Niederle and Vesterlund (2007), although aimed at gender differences, show that competitive incentives increase performance among men relative to performance with under a piece rate reward scheme, and that even among women, performance is at least as good under tournament incentives as under piece rate rewards.

${ }^{6}$ Our hypothesis is only with respect to the success rate and not to the allocation of time between the two tasks, as the allocation of time at the end is affected by the decisions made at the beginning of the tenminute period.

${ }^{7}$ In calculating the various averages, we first calculate the particular measure (such as success rate) for each individual and then average across individuals. Under PFP incentives, the average number of sequences attempted was 11 with a standard deviation of 6.69; under tournament, the average number of sequences attempted was 9.6 with a standard deviation of 6.78 . There were two outliers, one in each condition, who attempted over 30 sequences in 10 minutes (32 sequences under PFP and 33 sequences under Tournament.) 30 attempts is more than two standard deviations from the mean. Therefore, in our analysis and in the statistics presented above we exclude these two outliers.
} 
Table 1: Comparing the PFP and the Tournament Treatments

\begin{tabular}{|c|c|c|c|}
\hline & PFP & Tournament & P-value \\
\hline Total Performance & 33.95 & 32.99 & n.s. \\
\hline Attempted Sequences & 10.71 & 9.2 & $\mathrm{P}=0.083$ \\
\hline Correctly Solved Sequences & 8.54 & 7.29 & n.s. \\
\hline Success Rate & 0.79 & 0.72 & $\mathrm{P}=0.047$ \\
\hline Time on Sequences & 381.06 & 330.88 & $\mathrm{P}=0.025$ \\
\hline Time per Attempted Sequence & 48.67 & 50.79 & n.s. \\
\hline Time per Correctly Solved Sequence & 63.42 & 70.74 & n.s. \\
\hline Net Filing Rate & 1.02 & 1.06 & n.s. \\
\hline
\end{tabular}

\subsection{The Effect of Competitive Incentives}

The effect of tournament incentives on time allocation is best seen in figure $2 \mathrm{~B}$, which compares the minute-by-minute percentage of time devoted to solving sequences in the PFP and the tournament treatments. Figure $2 \mathrm{~B}$ strikingly illustrates that the effect of tournament incentives is neither due to a single episode nor due to a particular stage of the task. Rather, the effect of tournament incentives on time allocation stems from different time allocation decisions made throughout the entire 10 minutes of the study.

Figure 2: Allocation of Time

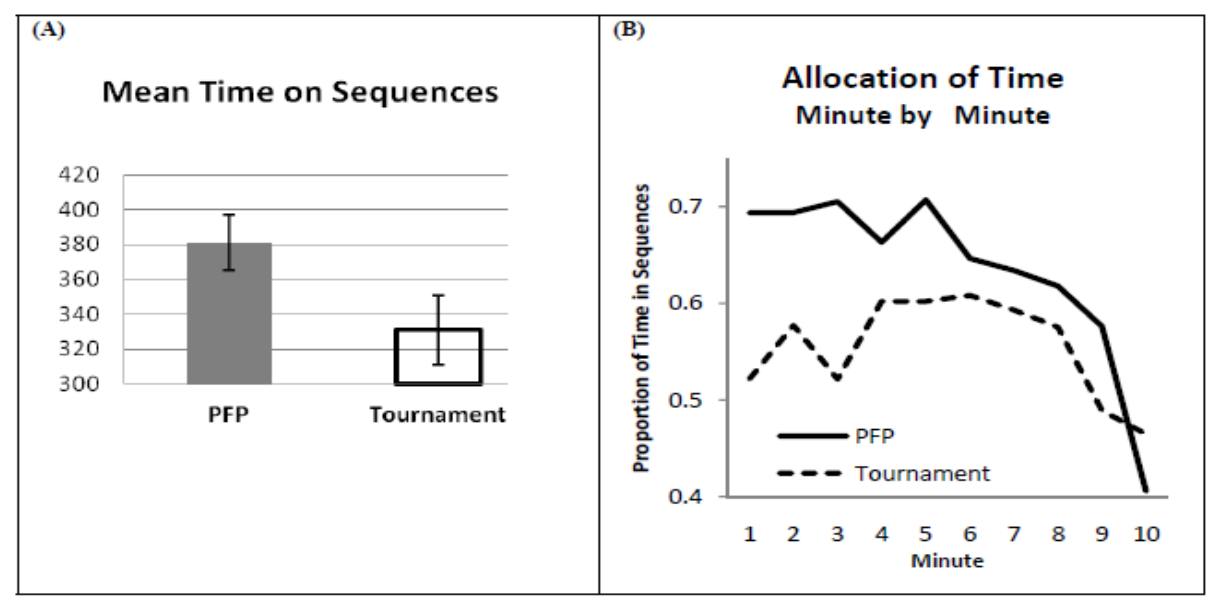

Source: Authors' calculations.

Note: $\mathrm{N}=73$ under PFP, $\mathrm{N}=59$ under tournament. The bars in panel A represent the standard error of the mean. 
To test the second part of Hypothesis 1 we calculate the success rate in solving sequences for each participant and then average these results across all individuals (see figure $3 \mathrm{~A})$. We find that the success rate is lower under competitive incentives (78.6 percent under PFP while only 72 percent under tournament). Labor effort can be captured by examining the average net filing rate which is the average speed of net filing across participants (see figure 3B).

A significantly lower success rate coupled with a higher net filing rate (although the latter is not statistically significant) indeed demonstrates that competitive incentives induce participants to work harder but not smarter.

Figure 3: Sequence Success Rate

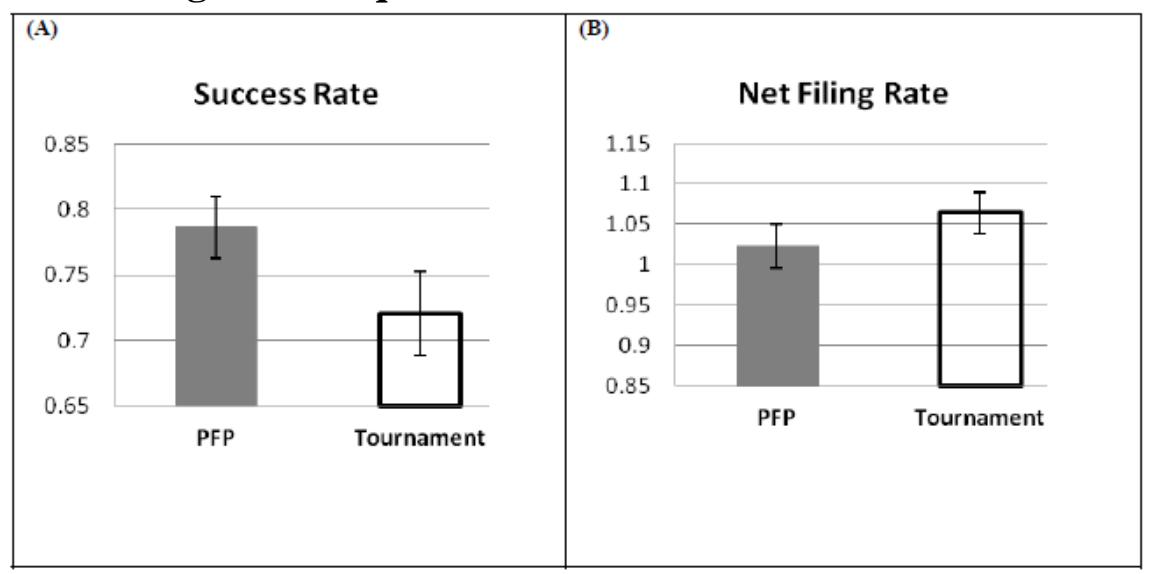

Source: Authors' calculations.

Note: Panel A: N= 73 under PFP, N=57 under Tournament; Panel B: N=69 under PFP, N=56 under Tournament. Bars represent the standard error of the mean.

Observation 1 (Tournament and cognitive effort): (i) Under competitive incentives participants devoted less time to the cognitive task than under the PFP incentives (330 second under competition versus 381 under PFP; $p=0.025$ ). (ii) The success rate in solving sequences is lower under tournament incentives-78.6 percent under PFP while only 72 percent under tournament incentives $(\mathrm{p}=0.047)$.

Clearly the two parts of Observation 1 may be interdependent: if participants are aware of the fact that under tournament they have a lower success rate, then their rational reaction would be to reduce the time they spend on solving sequences. The effect of competitive incentives on the success rate may be due to an effect on the effort expended, an effect on ability, or both. We may take the conservative economic interpretation of an effect on effort and treat ability as exogenous. However, under competitive pressure it is 
possible that even if one tries as much as she is able she would still not be able to perform as well as when she was not acting under pressure. Therefore it is possible that incentive schemes affect the ability to perform and such an effect should be taken into account whenever incentives are designed.

One possible explanation of Observation 1(i) is that it is indeed optimal for players to reduce the number of sequences they attempt to solve under tournament incentives. To clarify this point we calculated the optimal number of sequences for participants in the tournament condition, using our data on subjects' net filing rate, speed of solving a sequence, and the success rate. ${ }^{8}$

We first calculated the optimal number of sequences when the objective is to win the tournament and then compared this result to the optimal number of sequences calculated to maximize the payoff under the PFP incentives schedule.

When calculating the optimal number of sequences for winning the tournament, we calculated this result for each player and for every possible number of sequences he or she could solve in the given time frame, per the distribution of points. We then let each player compete against the distribution of points that the other players actually achieved in the tournament treatment (excluding the considered player) and then calculated each player's probability of winning. A given player's optimal number of sequences is the number that maximizes the player's probability of winning. We did this for all the players who both attempted to solve sequences and to file numbers and found that the average optimal number of sequences (that players should attempt to solve) is 7.82 . We then calculated the optimal number of sequences for maximizing payoff under the PFP incentives, meaning the number of sequences that players need to choose if they wish to maximize the expected number of points. The average optimal number of sequences under the PFP incentives is 7.72 sequences. Hence, the average optimal number of sequences under tournament is slightly (but not significantly) higher than the average optimal number of sequences under PFP incentives. Therefore, Observation 1(i) cannot

\footnotetext{
${ }^{8}$ We have this information for all the participants who attempted to solve at least one sequence and who filed at least one number.
} 
be explained by the individual players' optimal response to the different incentive schemes.

\subsection{Time Pressure}

If the lower success rate in the tournament treatment is the outcome of the competitive pressure felt by (some) participants, we would expect this effect to be manifested more strongly at the end of the tournament when the competitive pressure is likely at its highest level. We therefore divide the 10 minute experiment into two parts: the first seven minutes and the last three minutes. This division is arbitrary but we expect that in the tournament treatment participants would be more "pressured" in the last three minutes than in the first seven minutes. We compare the participants' success rate at the beginning and at the end of the treatment. In the tournament treatment success rate was 77.5 percent during the first seven minutes and only 57.9 percent during the last three minutes. This decline is highly significant $(\mathrm{p}<0.01)$. In the PFP treatment the success rate in the first seven minutes was 76.4 percent and 77.2 percent in the last three minutes. Of course it is possible that in the tournament treatment some low-ability individuals chose to solve sequences only during the last three minutes. To exclude this possibility we compared the success rate only for those individuals who solved sequences during both the first seven minutes and the last three minutes. We find the same pattern: there was no effect under PFP (76.12 percent success rate during the first seven minutes, and 77 percent success rate during the last three minutes) and there was a highly significant decline under competition (76.3 percent success rate during the first seven minutes compared with 57.5 percent success rate during the last three minutes; $p<0.01$.)

Observation 2 (Competitive Time Pressure): During the last three minutes of the tournament, the participants' success rate was significantly lower than in the first seven minutes. However, time pressure in and of itself has no such effect, as in the PFP treatment there was no reduction in participants' success rate during the last three minutes.

\subsection{Tournament and Risk Aversion}

Solving sequences is a risky task as players are uncertain about whether they will be able to solve a sequence correctly, and about how long it will take them to solve a sequence. In the PFP treatment risk aversion may be an important factor in determining 
the time allocation between the two tasks. The question comes down to whether the riskiness of the cognitive task drives the result reported in Observation 1.

In evaluating the overall risk that subjects faced in our experiment, one needs to separate the risk derived from the task they choose, and the risk that is derived from the incentives they face. In the PFP treatment subjects were paid according to their own performance; hence when they engage in the filing task they bear no risk. But in the tournament treatment subjects face the risk of losing the tournament, regardless of the task they choose. Under such an incentive scheme even the filing task yields uncertain outcome. As we will illustrate below it is not clear that the "risky" task is more risky than the "safe" task when players are facing tournament incentives.

Suppose a player has two choices. Choice A yields 22 for sure, while Choice B gives 35 with probability 50 percent and 10 with probability 50 percent. Under the PFP incentives, where the numbers are dollar amounts, choice B is risky while choice A is not. Whenever players are (sufficiently) risk averse, we would indeed expect them to prefer choice A over choice B. Now suppose that players are divided into pairs and face tournament incentives; the numbers now represent the number of points one can achieve. The player who earns the highest number of points wins the tournament and gets a prize; in case of a tie, the winner is determined by a flip of a fair coin. In such a competitive environment, although Choice A seems safe (earning 22 points for sure/is a sure bet), it is in fact as risky as choice B. Choosing either one-Choice A or Choice B-the individual bears the same exact risk. The probability of winning is 50 percent for each choice of action regardless of the choice of the player's opponent. For a similar reason, the filing task in our case is not risky under PFP incentives, but yields uncertain returns under competitive incentives.

We ran a simple choice experiment to illustrate the above argument. The experiment was conducted at the Harvard Decision Science Laboratory with 50 participated-20 men and 30 women - in three sessions. We use a within subject design, where participants were given two choices; choice A guaranteed a fixed amount of 22 while choice B was a lottery of 50-50 percent chance to win 35 or 10 points. In one task the amounts were marked in dollars and represented their final payoffs (equivalent to our PFP treatment). In the second task players were involved in a head to head tournament and the amounts were marked in points. The player that got the highest amount of points 
was the winner and got the prize of $\$ 40$ (in case of a tie we flipped a coin to determine the winner). The order of the tasks was different across sessions, and in all sessions, one of the choice tasks was randomly picked for payment at the end of the study.

Notice that in both tasks, the choice is between a sure amount and a lottery, where the amounts and the lottery chances were identical across the two tasks. The only difference is the environment - in one task one is paid according to her choice, while in the other the payment depends on a competition result. This is similar to the two tasks in the original study — the filing task seems "safe" while the sequence task seems "risky". If competition leads individuals to choose what seems safe, we would expect a higher percentage of individuals to choose the sure amount (choice A) under tournament incentives than under the PFP incentives. The experiment's findings were just the opposite. Participants choose the lottery more often under tournament incentives. Under tournament 68 percent of the subjects chose the "risky" option while under PFP incentives only 24 percent chose the "risky" option $(p<0.01)$. This is true for both males (35 percent vs. 75 percent; $\mathrm{p}<0.01$ ) and for females (17 percent vs. 63 percent; $\mathrm{p}<0.01$ ).

\subsection{Winners and Losers.}

Competitive incentives do not necessarily have a uniform effect on individuals: some people may be encouraged by and do better under competition, while others may get discouraged and perform worse due to competitive pressure. We therefore examine the effect of competitive incentive by subgroups. We first distinguish between winners and losers in the tournament treatment and compare their performance to the performance of the appropriate comparison group in the PFP treatment.

Table 1 presents the performance of the winners and the losers separately. We find that winners and losers spend statistically the same amount of time on solving sequences - the winners spend 347 seconds (approximately 5.78 minutes) on average while losers spend 313 second (approximately 5.22 minutes) on average, but this difference is not significant $(\mathrm{p}=0.39)$. Nevertheless, the winners' average score is 44.38 points, they solve on average 11.13 sequences, and their success rate is 85 percent while the losers' average score is 21.2 points, they solve only 7.20 sequences, and their success rate was 59 percent. 
Table 2: Winners and Losers in the Tournament Treatment

\begin{tabular}{llll}
\hline & $\begin{array}{l}\text { Winners } \\
\mathrm{N}=30\end{array}$ & $\begin{array}{l}\text { Losers } \\
\mathrm{N}=29\end{array}$ & $\mathrm{P}$-value \\
\hline \hline Total Performance & 44.38 & 21.21 & $\mathrm{P}=0.00$ \\
Attempted Sequences & 11.13 & 7.20 & $\mathrm{P}=0.001$ \\
Correctly Solved Sequences & 10 & 4.5 & $\mathrm{P}=0.00$ \\
Success Rate & .85 & .59 & $\mathrm{P}=0.00$ \\
Time on Sequences & 347.83 & 313.35 & $\mathrm{n} . \mathrm{s}$. \\
Time per Attempted Sequence & 47.56 & 54.14 & $\mathrm{n} . \mathrm{s}$. \\
Time per Correctly Solved Sequence & 56.18 & 86.97 & $\mathrm{P}=0.052$ \\
Net Filing Rate & 1.10 & 1.02 & n.s. \\
\hline Source: Authors' callations. Note: For & wing
\end{tabular}

Source: Authors' calculations. Note: For winners, N=30; for losers, N=29. Success rate, time per attempted sequence, and time per correctly solved sequence are based on individuals who actually solved a sequence. Pvalues are based on two-sided T-tests.

Observation 3: The winners in the tournament treatment are the participants with the higher success rate. Nevertheless, there was no difference between the tournament winners and losers with respect to the time they spent on solving sequences.

Next we split the PFP and the tournament participants into two groups each-aboveand below-median performers based on overall performance in that specific condition. ${ }^{9}$ We found that the success rate of the above-median performers across conditions is similar (85.64 percent under tournament vs. 84.96 percent under PFP). However, the success rate of the below-median performers is affected by the competitive environment: the success rate of the below-median performers in the tournament is 57.93 percent and it is significantly lower than the 72.45 percent success rate of the below-median PFP performers $(\mathrm{p}<0.05)$. As for time allocation: both the above- and below-median performers in the tournament seemed to spend less time solving sequences compared to above- and below-median PFP performers (respectively). Below-median performers in the PFP condition spent 366 seconds on sequences, while below-median performers in the tournament spent only 315 seconds on sequences. Similarly, above-median

\footnotetext{
${ }^{9}$ Since in the tournament treatment we had a random matching of pairs, the losers and winners are not necessarily all of low- or high-ability, respectively. This is because it is possible that two strong or two weak participants were competing against each other. For that reason we compare low (high) performers in the PFP condition to the low (high) performers in the tournament condition.
} 
performers in the PFP condition spent 397 seconds on sequences, while above-median performers spent only 347 seconds on sequences under tournament. However, the decline is significant only for the above-median performers $(\mathrm{p}=0.064$.)

Observation 4: The decline in the time spent on sequences under competitive incentives is evident across performance levels; however it is significant only among the high performers. The decline in the success rate, in contrast, characterizes only the low performers.

\section{The Gender Effect}

Recent studies have indicated that men and women respond differently to competitive incentives. ${ }^{10}$ Much to our surprise, not only did we find gender differences in response to competitive incentives, we also found gender differences in the benchmark PFP treatment.

\section{Observation 5 (PFP: Gender Effect):}

(i) Women devoted on average 360 seconds (6 minutes) to sequences solving while men devoted 419 seconds (approximately 7 minutes) to solving sequences $(\mathrm{p}=0.055)$.

(ii) On average women attempted to solve 8.9 sequences while on average men attempted to solve 14.1 sequences $(\mathrm{p}<0.01)$.

(iii) Women spent on the average 50.79 seconds per attempted sequence while men spent on average 44.58 seconds per attempted sequence (this difference is not statistically different).

(iv) Men and women had similar average success rates; 76.2 percent for men and 79.8 percent for women. ${ }^{11}$

Women's choice to devote less time to solving sequences cannot be the outcome of a lower success rate since in solving sequences they had success rates similar to men; in fact, although not statistically significant, women's average success rate in the PFP

${ }^{10}$ See Gneezy, Niederle, and Rustichini (2003) for gender differences in response to competition among college students, and Gneezy and Rutchini (2004) for gender differences in response to competition among children. See Niederle and Vesterlund (2007), Sutter and Rutzler (2010), as well as Datta Gupta, Poulsen, and Villeval (forthcoming) for gender differences in selecting into competitive environment. Gneezy, Leonard, and List (2009) suggest that these differences may be due to nurture rather than nature; see also Booth and Nolen (2012). For recent reviews see Croson and Gneezy (2009) and Bertrand (2011). Interestingly, two forthcoming papers find no such gender differences in competitiveness (either performance or preference) among Swedish and Colombian children (Dreber, Von Essen, and Ranehill 2011; Cárdenas, Dreber, Von Essen, and Ranehill 2011).

${ }^{11}$ There was no gender difference in the speed of the filing task-women's net filing rate was 1.00 while for men it was 1.04 . 
treatment is slightly higher than the men's. It is possible that the observed time allocation choice is the outcome of the gender difference in risk aversion and self-confidence (see, for example, Eckel and Grossman 2008a; for a review see Eckel and Grossman 2008b, as well as Croson and Gneezy 2009 and Bertrand 2011). As discussed, under PFP incentives solving sequences is riskier than filing numbers. Therefore a higher degree of risk aversion among women is a possible explanation for why women devote less time to sequence solving compared with men. Beyond risk aversion, lower self-confidence, which can affect one's own perception of success rate and time needed to solve sequences, may be also a factor explaining women's choice of spending less time on sequences.

Given the above gender differences, the reader may wonder whether the observed effect of tournament incentives is an artifact of having a different gender mix across treatments. In other words, if there were relatively more women participating in the tournament treatment than in the PFP treatment, then the different gender mix could explain the decline in the overall time devoted to solving sequences in the tournament treatment. However in our experiments there were relatively more women participating in the PFP treatment than in the tournament treatment, so we would expect the opposite effect. $^{12}$ Nevertheless, below we examine the effect of tournament incentives on each gender separately and at the end we will present a simple OLS regression that takes into account these relevant variables.

The overall performance was not different in the tournament treatment and the PFP treatment (measured by the average score in points in the tournament treatment, and average payoff in the PFP treatment). The average number of points for women under tournament was 29.12 compared with $\$ 30.98$ under PFP. The average number of points for men under tournament was 38.64 compared with \$39.64 under PFP. The differences for women and men are insignificant.

The Effect of Competitive Incentives on Women: Women's success rate in solving sequences declined from 79.87 percent under PFP to 67.18 percent under tournament $(\mathrm{p}<0.01)$, a sharp and strong decline of over 15 percent in the success rate. This decline

\footnotetext{
${ }^{12}$ In the PFP treatment, 48 women and 25 men participated; in the tournament treatment, 35 women and 24 men participated.
} 
was evident in the last three minutes of the experiment - a decline from 77.11 percent under PFP to 49.74 percent under tournament $(\mathrm{p}<0.01)$ - but was not evident during the first seven minutes. Under the PFP incentives women spent an average of 360 seconds (6 minutes) on solving numerical sequences, while under tournament incentives they spent on average only 308 seconds (about 5.13 minutes; $\mathrm{p}=0.066$ ). ${ }^{13}$ See figure 4 below for the minute-by-minute time allocation in the PFP and the tournament treatments.

The Effect of Competitive Incentives on Men: In the tournament treatment men reduced the amount of time they devoted to solving sequences from 419 seconds (almost 7 minutes) to 363 seconds (a little over 6 minutes) $(\mathrm{p}=0.059)$. The average number of sequences men attempted to solve decreased from 14.16 under PFP to 10.87 under tournament $(\mathrm{p}=0.045$.). However, the tournament incentives did not affect men's success rate, which was 76.23 percent in the PFP treatment and 78.69 percent in the tournament treatment.

Observation 6 (Gender and Tournament): (i) Both men and women reduce the time they spent on sequence solving when facing tournament incentives. (ii) Tournament incentives only affected the success rate of women. This effect is mainly due to pressure at the end of the tournament.

Figure 4: Allocation of Time, Minute-by-Minute

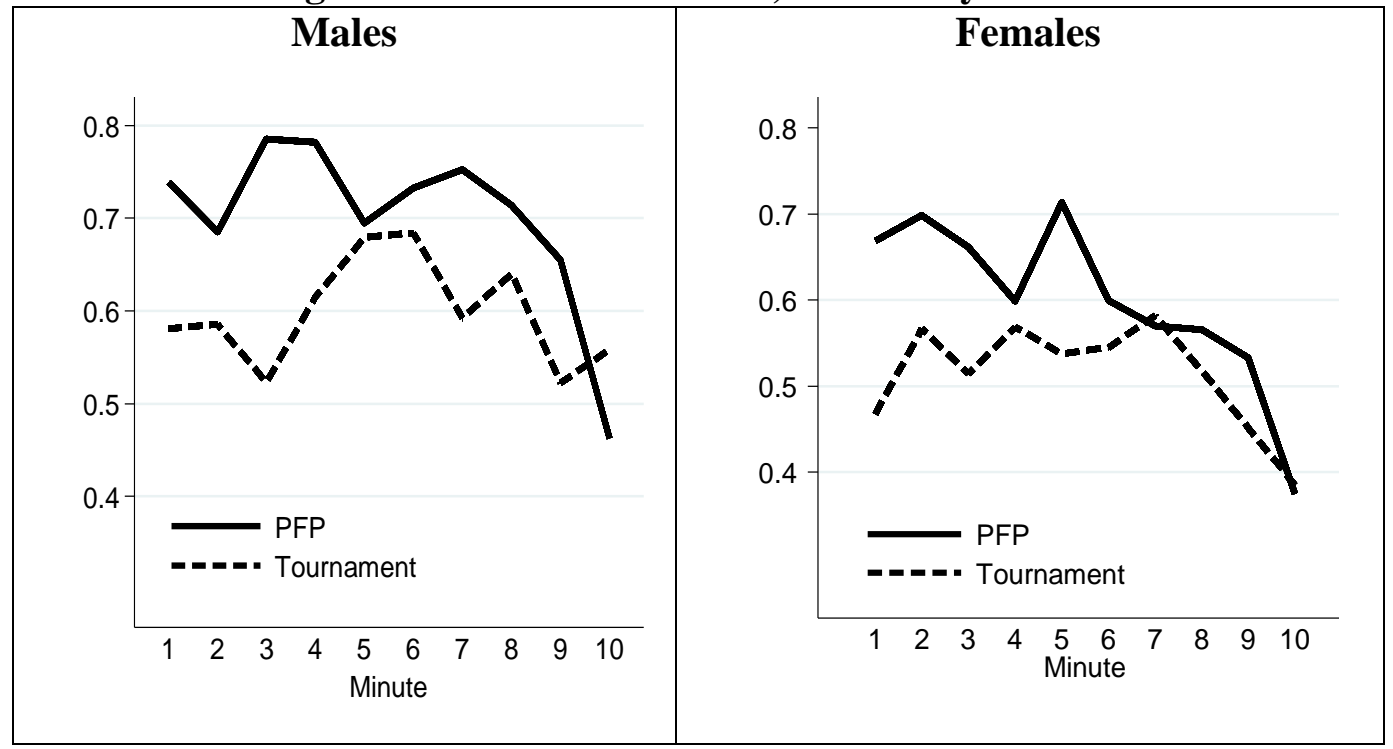

Source: Authors' calculations.

${ }^{13}$ This led to a significantly higher net filing among women (339.52 under tournament versus 258.71 under PFP; $\mathrm{p}=0.024)$. 
These results are also reflected in a regression analysis which controls for gender and age: we used an OLS regression of the success rate and the time devoted to solving sequences on a treatment dummy variable (that takes a value of 1 for a tournament treatment), gender (that takes a value of 1 for females), and age. The results are presented in table 3 .

\section{Table 3: OLS Regressions}

\begin{tabular}{|c|c|c|c|c|}
\hline & Success & $\begin{array}{l}\text { Time Allocated } \\
\text { to Sequences }\end{array}$ & Success & $\begin{array}{l}\text { Time Allocated } \\
\text { to Sequences }\end{array}$ \\
\hline $\begin{array}{l}\text { Treatment } \\
\text { (=1 for tournament) }\end{array}$ & $\begin{array}{l}-.075 \\
(-1.90)\end{array}$ & $\begin{array}{l}-52.381 \\
(-2.10)\end{array}$ & $\begin{array}{l}.017 \\
(0.28)\end{array}$ & $\begin{array}{l}-59.322 \\
(-1.45)\end{array}$ \\
\hline $\begin{array}{l}\text { Gender } \\
(=1 \text { for Females })\end{array}$ & $\begin{array}{l}-.030 \\
(-0.77)\end{array}$ & $\begin{array}{l}-53.030 \\
(-2.06)\end{array}$ & $\begin{array}{l}.038 \\
(0.71)\end{array}$ & $\begin{array}{l}-58.177 \\
(-1.65)\end{array}$ \\
\hline Treatment x Gender & & & $\begin{array}{l}.150 \\
(-1.89) \\
\end{array}$ & $\begin{array}{l}11.157 \\
(0.22) \\
\end{array}$ \\
\hline Age & $\begin{array}{l}-.018 \\
(-1.19)\end{array}$ & $\begin{array}{l}-7.209 \\
(-1.90)\end{array}$ & $\begin{array}{l}-.017 \\
(-1.19)\end{array}$ & $\begin{array}{l}-7.268 \\
(-1.90)\end{array}$ \\
\hline Constant & $\begin{array}{l}1.179 \\
(3.74)\end{array}$ & $\begin{array}{l}564.671 \\
(7.00)\end{array}$ & $\begin{array}{l}1.130 \\
(3.61)\end{array}$ & $\begin{array}{l}569.255 \\
(6.80)\end{array}$ \\
\hline $\mathrm{N}$ & 130 & 132 & 130 & 132 \\
\hline $\mathrm{R}^{2}$ & 0.037 & 0.089 & 0.064 & 0.089 \\
\hline
\end{tabular}

Note: t-statistics are in parenthesis; the number of observations is lower when analyzing the success rate compared with time allocation. This is due to participants who did not solve a single sequence.

As table 3 shows, we find that under competitive incentives the success rate is lower by 7.5 percentage points, which is approximately 9.5 percent of the average success rate under PFP ( $\mathrm{p}=0.06)$. Under tournament incentives the time allocated to solving sequences is lower by 52.38 seconds, which is about 13.7 percent of the average time devoted to sequences under PFP $(\mathrm{p}=0.038)$. Adding an interaction term to examine whether competition has a differential gender effect confirms that the decline in the success rate under tournament is solely a female effect $(\mathrm{p}=0.06)$, while the decline in the time allocated to solving sequences is similar for both men and women (the interaction term is not significant).

Interestingly, in our settings women won the tournament at a similar proportion as did men in contrast to previous findings (see table A1; Gneezy, Niederle, and Rustichini 
2003, and Gneezy and Rustchini 2004). Specifically, 16 out of the 35 women who participated in the tournament treatment won while 14 out 24 men who participated in the tournament treatment won (Fisher exact test; $\mathrm{p}=0.43$ ). Furthermore, by randomly matching participants in the tournament condition, and repeating this test, we find that out of 100 random matches there were only eight instances with significant differences in the winning proportions across genders. The result is that we reject the hypothesis that the average $\mathrm{z}$ statistics across all 100 random matches is equal to or greater than 1.96. Therefore, this lack of difference in the winning proportions across gender is not an artifact of the actual matching we used in the study. ${ }^{14}$

\section{Concluding Comment}

Modern organizations typically provide workers, managers, students, or researchers strong and competitive incentives in order to induce them to exert more effort. However, there are several studies showing that this intuitive effect of competitive incentives does not always hold. For example, Gneezy and Rustichini (2000) and Frey and Jegen (2001) demonstrated the crowding out effect, where strong explicit incentives may crowd out different types of social motivation and may result in less effort (for a recent survey see Gneezy, Meier and Rey-Biel 2011).

The main result of this paper focuses on yet another shortcoming of strong competitive incentives - these may induce agents to work harder but not necessarily smarter. The distinction between these two types of efforts should be taken into account by organizations when they design their incentives schemes. There are many situations in which the labor and the cognitive efforts cannot be directly observed, are not verifiable, and cannot be incentivized separately. In these cases organizations need to evaluate the relative importance and implications of different combinations of cognitive and labor efforts. If firms have strong preferences for motivating their employees to work smarter but cannot directly incentivize cognitive effort, the implication of our finding is that these organizations should refrain from using competitive incentives.

\footnotetext{
${ }^{14}$ In generating the random matching we tried both (1) using all participants, including those who attempted over 30 sequences, and (2) excluding those who attempted over 30 sequences. In the latter case we simply dropped the person left with no competitor, and we found similar results.
} 


\section{References}

Ariely Dan, Uri Gneezy, George Loewenstein, and Nina Mazar. 2009. "Large Stakes and Big Mistakes." Review of Economic Studies 76(2): 451-469.

Baumeister, Roy F. 1984. "Choking under Pressure: Self-Consciousness and Paradoxical Effects of Incentives on Skillful Performance.” Journal of Personality and Social Psychology 46(3): 610-620.

Baumeister, Roy F. and Carolin J. Showers. 1986. "A Review of Paradoxical Performance Effects: Choking under Pressure in Sports and Mental Tests." European Journal of Social Psychology 16(4): 361-383.

Beilock, Sian L., Catherine A. Kulp, Lauren E. Holt, and Thomas H. Carr. 2004. "More on the Fragility of Performance: Choking Under Pressure in Mathematical Problem Solving." Journal of Experimental Psychology: General 133(4): 584-600.

Bertrand Marianne. 2011. "New Perspectives on Gender." In Handbook of Labor Economics, Volume 4b, ed. Orly Ashenfelter and David Card, 1543-1590. Amsterdam: North Holland.

Booth Alison, and Patrick Nolen. 2012. "Choosing to Compete: How Different are Girls and Boys?” Journal of Economic Behavior \& Organization 81(2):542-555.

Bull Clive, Andrew Schotter, and Keith Weigelt. 1987. "Tournaments and Piece Rates: An Experimental Study.” Journal of Political Economy 95(1): 1-33.

Cárdenas Juan-Camilo, Anna Dreber, Emma Von Essen, and Eva Ranehill. Forthcoming. "Gender Differences in Competitiveness and Risk Taking: Comparing Children in Colombia and Sweden." Journal of Economic Behavior \& Organization.

Croson, Rachel, and Uri Gneezy. 2009. "Gender Differences in Preferences.” Journal of Economic Literature 47(2): 448-474.

Datta Gupta, Nabanita, Anders Poulsen, and Marie Claire. Villeval. Forthcoming. "Gender Matching and Competitiveness: Experimental Evidence." Economic Inquiry.

Dreber, Anna, Emma Von Essen, and Eva Ranehill. 2011. "Outrunning the Gender Gap_Boys and Girls Compete Equally.” Experimental Economics14(4): 567-582.

Eckel Catherine C. and Philip J. Grossman 2008a. "Forecasting Risk Attitudes: An Experimental Study using Actual and Forecast Gamble Choices." Journal of Economic Behavior \&Organization 68 (1): 1-17.

Eckel Catherine .C. and Philip J. Grossman. 2008b. "Men, Women and Risk Aversion: Experimental Evidence." In Handbook of Experimental Economics Results, ed. Charles R. Plott and Vernon L. Smith, 1061-1073. Amsterdam: Elsevier. 
Ehrenberg Ronald G., and Michael L. Bognanno. 1990. "Do Tournaments Have Incentive Effects?” Journal of Political Economy 98(6): 1307-1324.

Frey, Bruno. S., and Reto Jergen. 2001. "Motivation Crowding Theory.” Journal of Economic Surveys 15(5): 589-611.

Fehr, Ernst, and Armin Falk. 2002. "Psychological Foundation of Incentives." European Economic Review 46(4-5): 687-724.

Gneezy, Uri, and Aldo Rustichini. 2000. "Pay Enough or Don't Pay at All.” Quarterly Journal of Economics 115(3): 791-810.

Gneezy, Uri, Muriel Niederle, and Aldo Rustichini. 2003. "Performance in Competitive Environments: Gender Differences.” Quarterly Journal of Economics 118(3): 10491074.

Gneezy, Uri, and Aldo Rustichini. 2004. "Gender and Competition at a Young Age." American Economic Review Papers and Proceedings 94(2): 377-381.

Gneezy, Uri, Kenneth L. Leonard, and John A. List. 2009. "Gender Differences in Competition: Evidence from a Matrilineal and a Patriarchal Society." Econometrica 77(5): 1637-1664.

Gneezy, Uri, Stephan Meier, and Pedro Rey-Biel. 2011. "When and Why Incentives (Don't) Work to Modify Behavior.” Journal of Economic Perspectives 25(4): 191-210.

Kocher Martin G., Marc V. Lenz, and Matthias Sutter. 2010. "Psychological Pressure in Competitive Environments: Evidence from a Randomized Natural Experiment: Comment", IZA Discussion Paper Number 4846. Available at http://ftp.iza.org/dp4846.pdf.

Kremer, Michael, Edward Miguel, and Rebecca Thornton. 2009. "Incentives to Learn." Review of Economics and Statistics 91(3): 437-456.

Lazear, Edward P., and Sherwin Rosen. 1981. "Rank-Order Tournaments as Optimum Labor Contracts.” Journal of Political Economy 89(5): 841-864.

Lazear, Edward P. 2000. "The Future of Personnel Economics." Economic Journal 110(467): F611-F639.

Niederle, Muriel, and Lise Vesterlund. 2007. "Do Women Shy Away from Competition? Do Men Compete Too Much?” Quarterly Journal of Economics 122(3): 1067-1101.

Sutter, Matthias, and Daniela Rützler. 2010. "Gender Differences in Competition Emerge Early in Life." IZA Discussion Paper Number 5015. Available at http://ftp.iza.org/dp5015.pdf. 


\section{Appendix}

Table A1: Winners and Losers in the Tournament Treatment, by Gender

\begin{tabular}{|l|l|l|l|}
\hline & $\begin{array}{l}\text { Winners } \\
\text { N=30 } \\
\text { Men=14, Women=16 }\end{array}$ & $\begin{array}{l}\text { Losers } \\
\text { N=29 } \\
\text { Men=10, Women=19 }\end{array}$ & Ttest \\
\hline Total Performance & 44.38 & 21.21 & $\mathrm{p}=0.00$ \\
Women & 39.75 & 20.17 & $\mathrm{p}=0.00$ \\
Men & 49.67 & 23.18 & $\mathrm{p}=0.00$ \\
\hline Success rate & 0.84 & 0.58 & $\mathrm{p}=0.00$ \\
Women & 0.80 & 0.56 & $\mathrm{p}=0.00$ \\
Men & 0.89 & 0.64 & $\mathrm{p}=0.00$ \\
\hline Time on Sequences & 347.83 & 313.35 & $\mathrm{p}=0.39$ \\
Women & 302.97 & 313.37 & $\mathrm{p}=0.85$ \\
Men & 399.11 & 313.30 & $\mathrm{p}=0.14$ \\
\hline Net File Rate & 1.10 & 1.02 & $\mathrm{p}=0.13$ \\
Women & 1.12 & 1.00 & $\mathrm{p}=0.057$ \\
Men & 1.07 & 1.06 & $\mathrm{p}=0.88$ \\
\hline
\end{tabular}

